\title{
3. SEDIMENT FLUXES BASED ON AN ORBITALLY TUNED TIME SCALE 5 MA TO 14 MA, SITE $926^{1}$
}

\author{
Nicholas J. Shackleton ${ }^{2}$ and Simon Crowhurst ${ }^{2}$
}

\begin{abstract}
We have developed a detailed time scale for the late Miocene and later middle Miocene by correlating lithologic cyclicity observed at Site 926 to the astronomically determined variations in northern hemisphere summer insolation. Most of the equivalent section at Site 925 can be correlated in the same manner. The validity of the phase relationship that we have assumed, whereby maximum terrigenous content is correlated with peak insolation, is supported by examining the benthic $\delta^{18} \mathrm{O}$ data from the same site. The time scale is probably accurate to the level of the individual precession cycle back to about $7 \mathrm{Ma}$ and in many intervals back to $13 \mathrm{Ma}$; elsewhere, there are intervals where further work may require adjustments of one or more precession cycles.

At least in the upper part of the section investigated, we conclude that the lithologic signal is present because the input of terrigenous material to the Ceara Rise varied inversely with northern hemisphere summer insolation. At the same time, dissolution of foraminifers in the sediment as well as $\delta^{13} \mathrm{C}$ varied, chiefly in response to obliquity, with a significant phase lag that probably reflects the long residence time of carbon and nutrients in the ocean.
\end{abstract}

\section{INTRODUCTION}

The sediments recovered during Leg 154 provide a remarkable opportunity to improve the geological time scale of the late Neogene, using orbital tuning. Perhaps the most striking feature of the cores, observed on board ship as the sediments were recovered, was the pervasiveness of sedimentary cycles of decimeter scale throughout all the sites. In addition, there were frequent observations (e.g., Fig. 1) of the "bundling" that characterizes sequences that have been controlled by precession cycles. The cyclicity in the sediments, so apparent to visual inspection, was also evident in several of the parameters measured on board, including magnetic susceptibility and measured reflectance. Thus it became clear on board ship that there would be opportunities for an astronomical calibration of the time scale, using the methods pioneered by Imbrie et al. (1984) in Quaternary deep-sea cores, by Hilgen (1991a; 1991b) in sequences exposed in southern Italy, and by Shackleton et al. (1995b) in Ocean Drilling Program (ODP) Leg 138 sediments.

In this paper we describe a newly developed time scale for the late Miocene and a part of the middle Miocene that is primarily based on Site 926, and is applied to Site 925 (providing some verification). The following steps were used. First, we constructed an age model on the basis of shipboard biostratigraphy, using the time scale of Shipboard Scientific Party (1995a), which was based largely on Shackleton et al. (1995b). Second, we calibrated a time scale, working back in time from $5 \mathrm{Ma}$, by matching the high-frequency shipboard magnetic susceptibility variations in a spliced record to the orbital insolation record of Laskar et al. (1993). Third, we retuned the sequence of cores from the individual holes from Site 926, and where possible cores from each hole from Site 925. Finally, we carried out statistical evaluations and compared our results with those of Hilgen et al. (1995).

${ }^{1}$ Shackleton, N.J., Curry, W.B., Richter, C., and Bralower, T. (Eds.), 1997. Proc. ODP, Sci. Results, 154: College Station, TX (Ocean Drilling Program).

${ }^{2}$ University of Cambridge, Godwin Laboratory, Free School Lane, Cambridge, CB2 3RS, United Kingdom. NJS5@cam.ac.uk

\section{BIOSTRATIGRAPHY}

Remarkably high resolution was achieved in the shipboard biostratigraphy for calcareous nannofossils and planktonic foraminifers. Initially, age models were developed on the basis of the compilation given in the Shipboard Scientific Party (1995a). For the calcareous nannofossils, these were chiefly based on the Leg 138 time scale of Shackleton et al. (1995b), which was based on orbital tuning to the base of the Pliocene, and was extended by these workers using an interpretation of the spacing of seafloor magnetic anomalies presented by Cande and Kent (1992). The ages of the planktonic foraminiferal datums were derived by recalibrating the detailed biostratigraphy of Chaisson and Leckie (1993) to the Leg 138 time scale.

\section{ORBITAL SOLUTION}

There have been many attempts to calculate the past history of Earth's orbit and of its rotational axis (Berger, 1988; Berger and Loutre, 1991; Quinn et al., 1991; Laskar et al., 1993). The calculations can be thought of in two principal parts. First, the orbital history is determined treating the Earth-moon system as a point mass. Successive advances in this aspect of the solution have arisen from two factors: improvements in the accuracy of estimates of the masses and motions of the planets, and the availability of increased computing power, which permits higher order terms to be included in the calculations. The second step is to determine the contribution of the Earthmoon system. To calculate the history of insolation distribution, the two solutions must be combined, because climate is determined mainly by the orientation of the Earth's rotational axis with respect to its orbit around the sun rather than by the eccentricity of the orbit and its orientation with reference to the stars. Laskar et al. (1993) have generated a solution for the Earth-moon system that incorporates the effect of tidal friction. Tidal friction affects the rotation rate of the Earth and hence its shape, which is fundamental to precession and to obliquity variations. The calculations made by Laskar et al. (1993) show that a small change in the value assumed for tidal friction has a different proportional effect on the precession and the obliquity frequencies. Thus the relative timing of obliquity and precession cycles 

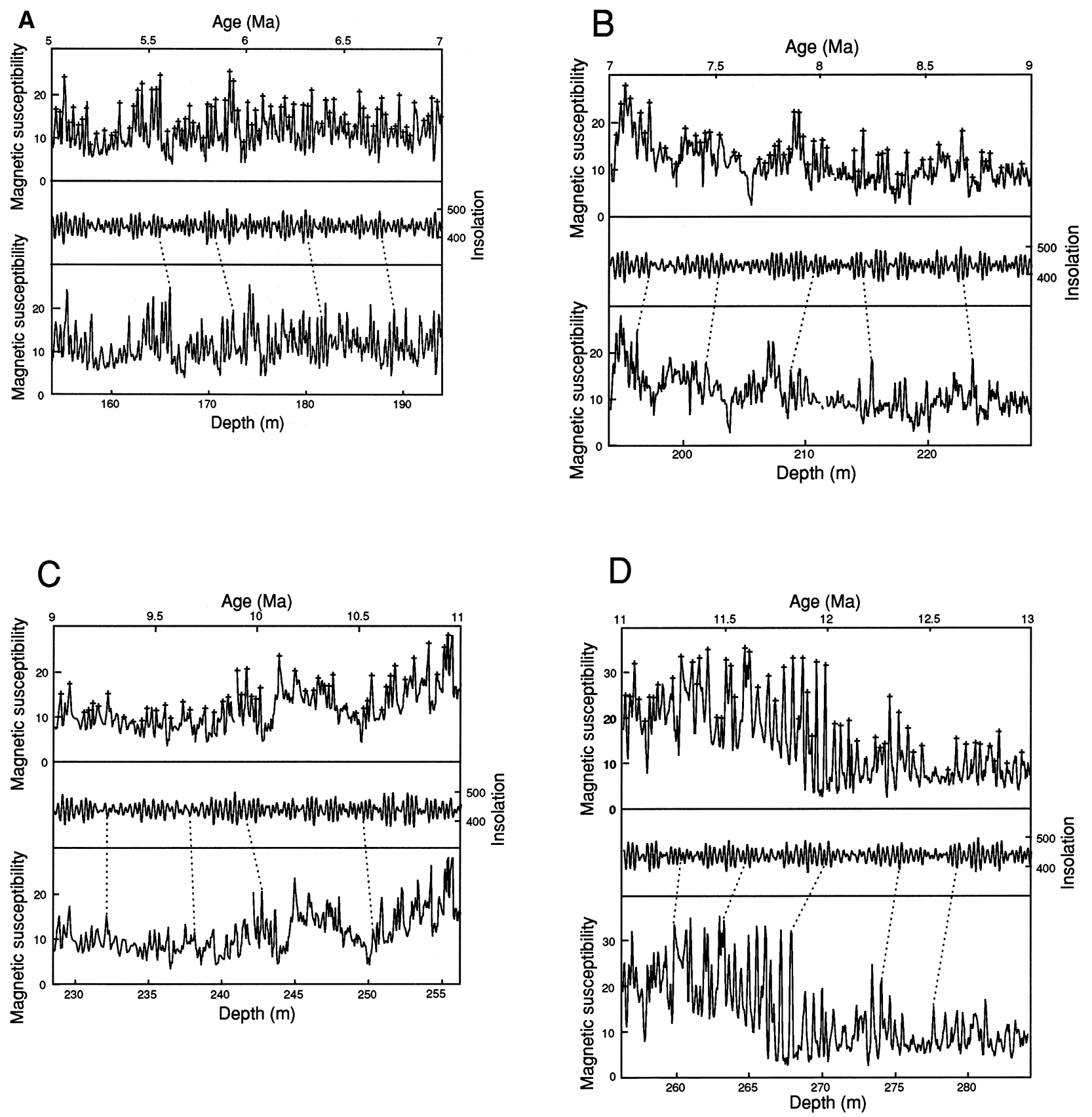

Figure 1. Tuned time scale as applied to magnetic susceptibility in the shipboard splice of Site 926 compared with summer insolation at about $65^{\circ} \mathrm{N}\left(\mathrm{W} / \mathrm{m}^{2}\right)$ from the orbital calculations of Laskar et al., (1993). A. 5 to 7 Ma. B. 7 to 9 Ma. C. 9 to 11 Ma. D. 11 to 13 Ma. E. 13 to 15 Ma. The section older than 14 Ma is not tuned. In each panel the magnetic susceptibility data are shown below vs. depth, and above vs. age with a cross marking each control point.

in successively older eccentricity maxima changes in a manner that is determined by the value adopted for tidal friction. Lourens et al. (in press) have carried out faunal and stable isotope investigations in some of the Pliocene sections that were first tuned by Hilgen (1991b), and they concluded that a consistency in phase relationships through the Pliocene is best maintained by using the solution La90 $(1,1)$. This solution assumes present-day values for both the dynamical ellipticity of the Earth and for tidal dissipation, and it agrees well with the numerical solution of Quinn et al. (1991) for the past 3 m.y. To maintain consistency with their work and with that of Hilgen et al. (1995) for the late Miocene, we have adopted the same orbital solution.
To generate a convenient tuning target, we combined obliquity and precession (reversed sign) so as to simulate midsummer insolation at $65^{\circ} \mathrm{N}$. In contrast to Hilgen (1991b), Hilgen et al. (1995), and Lourens et al. (in press), we have not assumed any lag between the tuning target and the lithologic signal. Hilgen (1991a) justified the lag that has been used in tuning the Italian sections on the basis of the lag that is observed between calculated insolation and the late Pleistocene sapropels of the Mediterranean. Modeling results do suggest that the Indian monsoon system is affected by the extent of Northern Hemisphere glaciation, as well as by insolation (Kutzbach and Guetter, 1984), so that the assumption of a lag is justified at least for 


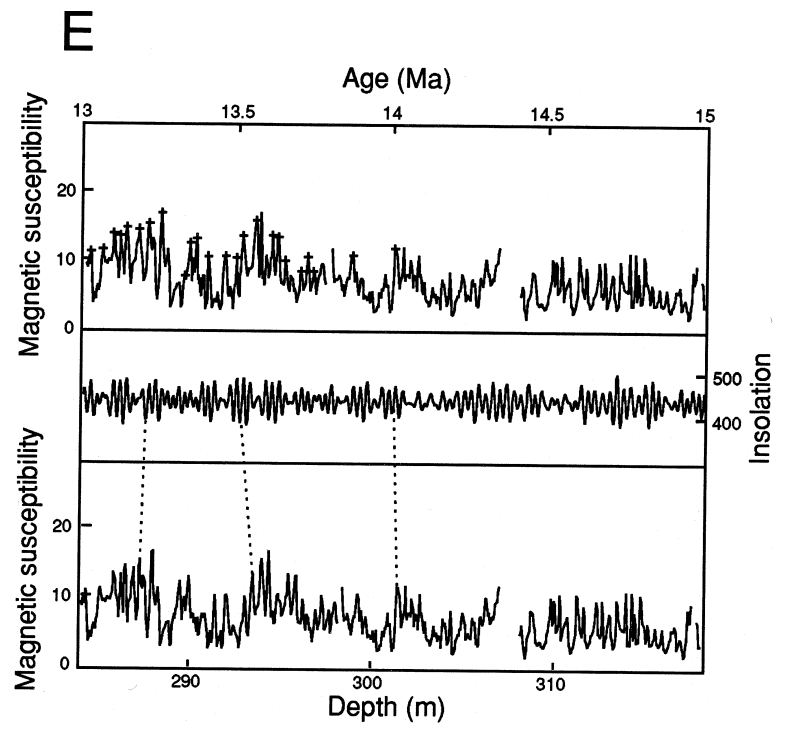

Figure 1 (continued).

the Pleistocene. However, in the absence of an identified mechanism for generating a lag during the Pliocene and Miocene in the region that we are dealing with, we consider that our low-latitude climate records should be assumed to have responded to insolation without delay.

\section{TUNING METHODS}

The primary signal that we used for tuning is magnetic susceptibility, which rises roughly in proportion to the concentration of terrigenous matter in the otherwise carbonate-dominated sediment. Maxima in magnetic susceptibility are less affected by background noise in the susceptibility record than are minima, so that we have generated age models exclusively by assigning ages to susceptibility maxima (carbonate concentration minima). In the initial stages we experimented with two contrasting models, one assigning susceptibility maxima to Northern Hemisphere summer insolation maxima and the other assigning them to Northern Hemisphere insolation minima (i.e., to southern hemisphere summer insolation maxima). The first of these models was rejected because it gave rise to inconsistent phase relationships in the obliquity band (specifically, it gave rise to a situation whereby positive $\delta^{18} \mathrm{O}$ in benthic foraminifers was in phase with maximum insolation at high latitudes). The model adopted, whereby a higher terrigenous fraction is associated with lower Northern Hemisphere summer insolation, is also the relationship that applies in the uppermost part of the record (Curry et al., this volume) although this does not necessarily indicate that the same mechanism has operated throughout.

To permit stacking of data from all the holes at a particular site, we aimed to use as many insolation minima as possible as age control points, while avoiding the use of any age controls that appear to generate unreasonable changes in implied sedimentation rate. The question of what is "unreasonable" in this context is partially answered by examining the apparent differences between holes in sedimentation rates estimated over the same time interval; these differences probably arise from physical disturbance during coring, from differences in multisensor track (MST) sampling intervals, and from uncertainties in the MST measurements themselves. Variations of $\pm 20 \%$ in apparent sedimentation rate from hole to hole are commonplace. To mini- mize the added variability in flux estimates that derives from this scatter, we used the mean for all holes for which estimates were available, of the estimated linear sedimentation rate between each pair of control points.

First, a time scale was generated using the shipboard splice (Shipboard Scientific Party, 1995b; fig. 12), but we examined the data from individual holes in subsequent work. This enabled us to determine whether a particular jump in apparent sedimentation rate was present in all holes or only in a single hole. In the latter case, coring disturbance in that hole is a likely cause. To generate the most reliable mean sedimentation rates, sections of sediment that appeared to be seriously affected by coring disturbance were excluded prior to stacking data from the three holes.

The same approach was subsequently taken for the record of Site 925. However, this site contains several slumps that were noted on board ship, and over some intervals the tuning was considerably less straightforward than it was at Site 926. The most important reason is probably that the carbonate content is higher at Site 925 than at Site 926, and that in the upper Miocene this results in very low amplitude lithologic cyclicity as monitored in the MST data.

\section{RESULTS}

The time scale is presented in Tables 1 and 2 (on CD-ROM in back pocket of this volume) in terms of a series of insolation minima as calculated in the Laskar $(1,1)$ astronomical solution, and a set of corresponding depths and sample identifiers for each hole at Sites 926 (Table 1) and 925 (Table 2). Tables 1 and 2 identify the controls that apply to samples used in the shipboard splice. Tables 1 and 2 also indicate those control points that represent the top, and the base, of each section of core that we have used in generating stacked records. Figure 1 illustrates the time scale as it applies to the shipboard splice for Site 926. The makeup of this splice is documented by Shipboard Scientific Party (1995b; fig. 12), whereas the relationship between the data from all the individual holes is illustrated by Shipboard Scientific Party (1995b) in their figure 10.

Figure 2 compares published ages for datums observed on board ship, with the age-depth plot for Site 926 that we developed by tuning. The implications of the tuned time scale for biostratigraphy are discussed by Raffi et al. (this volume) on the basis of shore-based observations. Here, we merely point out that tuned ages generally agree very well with published ages for the uppermost Miocene and basal Pliocene. For these intervals, the published ages were already based on astronomical tuning as compiled by Shackleton et al. (1995a). Ages for the remainder of the late Miocene are significantly older, by about 100 k.y., than previously published age estimates. However, the discrepancy does not increase at older ages, and indeed the tuned ages appear to converge with published ages at the base of the tuned interval. This implies that the radiometric tie point age of $14.80 \mathrm{Ma}$ for C5Bn.1n (t), used in the seafloor spreading time scales of Cande and Kent (1992) and of Shackleton et al. (1995b), is probably approximately correct.

\section{STATISTICAL EVALUATION}

We used cross-spectral analysis and complex demodulation in our evaluation of the time scale and its implications. Shipboard data (MST and reflectance) from the three holes investigated at Site 926 were stacked by interpolating them at 3-k.y. intervals using a gaussian weighting method (Shackleton and Imbrie, 1990; W. Howard, unpubl. data), using a total window width of 8.99 k.y. A gap code (-9999) was inserted where no data fell within the window. The use of a window that is less than three times the sampling interval is conservative in that 
Figure 2. Calcareous nannofossil biostratigraphic datum levels as determined aboard ship, plotted vs. the time scale of the Shipboard Scientific Party (1995a). The line represents the age-depth relationship determined in this paper; mcd $=$ meters composite depth.

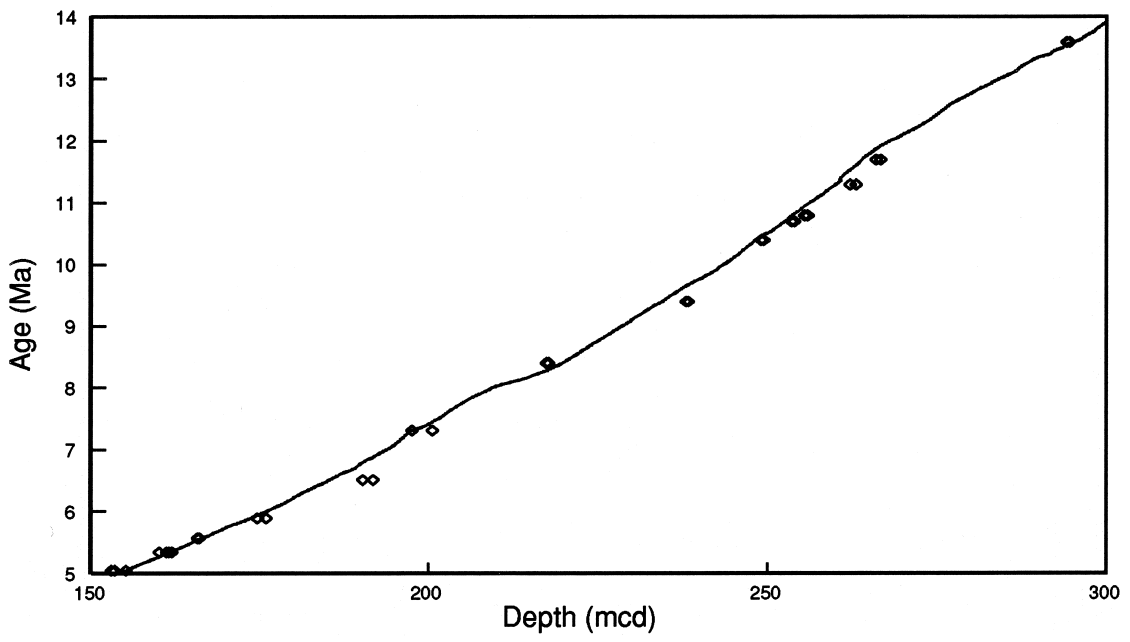

it ensures that there are never more interpolated points in a given interval than there were original data points. Data derived from discrete sampling (\% coarse fraction and stable isotope data) were interpolated by the gaussian weighting method at $6 \mathrm{k} . \mathrm{y}$. intervals (which represents almost exactly the mean sampling interval for the entire $5 \mathrm{Ma}$ to $14 \mathrm{Ma}$ period) using a total window width of 17.99 k.y. Spectral analysis was based on the methods in Jenkins and Watts (1968). For complex demodulation, the interpolated series used for spectral analysis was reinterpolated linearly at 1-k.y. intervals, including interpolating across the data gaps. For obliquity we demodulated at a central frequency of 0.0244 cycles/k.y. and used a low-pass Tukey filter with 200 weights and a $50 \%$ cutoff at 0.006 cycles/k.y. For precession we demodulated at a central frequency of 0.048 cycles/k.y. and used a low-pass Turkey filter with 100 weights and a $50 \%$ cutoff at 0.015 cycles/k.y.

As mentioned in the introduction, the lithologic records that we have tuned to an orbital time scale appear to display a strong precession signal. Shackleton et al. (1995c) have suggested that in this situation the most appropriate method for evaluating the reliability of the time scale is complex demodulation. Figure 3 shows the result of complex demodulation of the orbitally tuned magnetic susceptibility record of Site 926 (dashed) at a central frequency of 0.048 cycles/k.y. (21-k.y. period). Also shown (solid) is the calculated record of orbital eccentricity (Laskar et al., 1993). Figure 3 also shows the analogous data for Site 925 (dotted). It is visually clear that a good match exists between the amplitude modulation in the magnetic susceptibility data and orbital eccentricity. This visual appearance is confirmed by cross-spectral analysis (Fig. 4), which shows that in both sites the amplitude of the precession component is highly coherent with both the 400-k.y. and the "100-k.y." (actually 123-k.y. and 96-k.y.) components of eccentricity in both the upper and the lower halves of the records. However, one should be cautious in interpreting this result. An evaluation of Figure 3 can be made in two stages. First, at the level of the 400-k.y. component of the eccentricity cycle, it seems likely that the tuning is correct over the whole interval to about 13.7 Ma, because the amplitude of the signal as demodulated appears to rise with every 400-k.y. cycle. However, at the level of the 100 k.y. component of eccentricity there are significant mismatches in several other older sections, suggesting that correlation errors of one or two precession cycles could be present. In the interval between $11 \mathrm{Ma}$ and $12.5 \mathrm{Ma}$ carbonate dissolution cycles with a 41-k.y. period dominate the data to a point that the precession cycles are hard to detect, and the amplitude variations shown in that part of Figure 3 are less reliable. However, in the interval between $12.5 \mathrm{Ma}$ and $14 \mathrm{Ma}$ (the base of the tuned section) the amplitude modulation is again very clear, suggesting that the tuning has been correctly carried through the highly dissolved interval above. The evaluation of additional data, including the new reflectance data of Harris et al. (this volume) and the stable isotope data of Shackleton and Hall (this volume) may improve the accuracy of the correlations to the orbital template.

Backman and Raffi (this volume) show that the estimated age for the first appearance of Discoaster berggrenii on our time scale is over $100 \mathrm{k} . \mathrm{y}$. younger than expected. In view of this discrepancy, we attempted to retune the data in the interval $8 \mathrm{Ma}$ to $9 \mathrm{Ma}$. However, we were unable to find a plausible tuning that eliminated this apparent discrepancy. The reason is that at present we have three groups of susceptibility peaks tuned to insolation minima in the three intervals of high orbital eccentricity centered on about 8.18, 8.28, and 8.38 Ma. This grouping reflects the longer 400 k.y. eccentricity cycle (Fig. 3).

To investigate the possibility that the amplitude modulation is excessively biased by the intervals with high magnetic susceptibility, we also investigated the logarithm of the ratio of noncarbonate to carbonate as derived (see below) from the MST data. Complex demodulation of this record at a central frequency of 0.048 cycles $/ k . y$. shows a very similar measure of agreement with orbital eccentricity and is not shown here.

When a new geological record is first tuned astronomically, it is inevitable that the question of phase lag must be discussed. Here we have deviated from the approach of Hilgen (1991a; 1991b) and Lourens et al. (in press), and have assumed zero phase lag between midsummer Northern Hemisphere insolation and the lithologic cycles. In contrast Hilgen (1991a; 1991b) and Lourens et al. (in press) assumed that in the Pliocene, as in the late Pleistocene, there was a phase lag between insolation forcing and oceanographic response. Initially our assumption was made on the basis of simplicity; the low-latitude climate system is likely to respond to changes in the distribution of insolation without significant delay, in the absence of any additional lagging effects arising from slow ice-sheet response. Although this assumption is not directly testable, its plausibility may be checked by investigating the phase of other components of the climate system. We have investigated the benthic $\delta^{18} \mathrm{O}$ record for the interval 4.944 Ma to $7.35 \mathrm{Ma}$, for which interval we have continuous data (Shackleton and Hall, this volume). Cross-spectral analysis (Fig. 5B; Table 3 ) shows that on the susceptibility-based time scale, negative benthic $\delta^{18} \mathrm{O}$ has zero phase lag with respect to high-latitude insolation at the main obliquity frequency, which is consistent with our initial assumption regarding the association between maximum summer inso- 
A

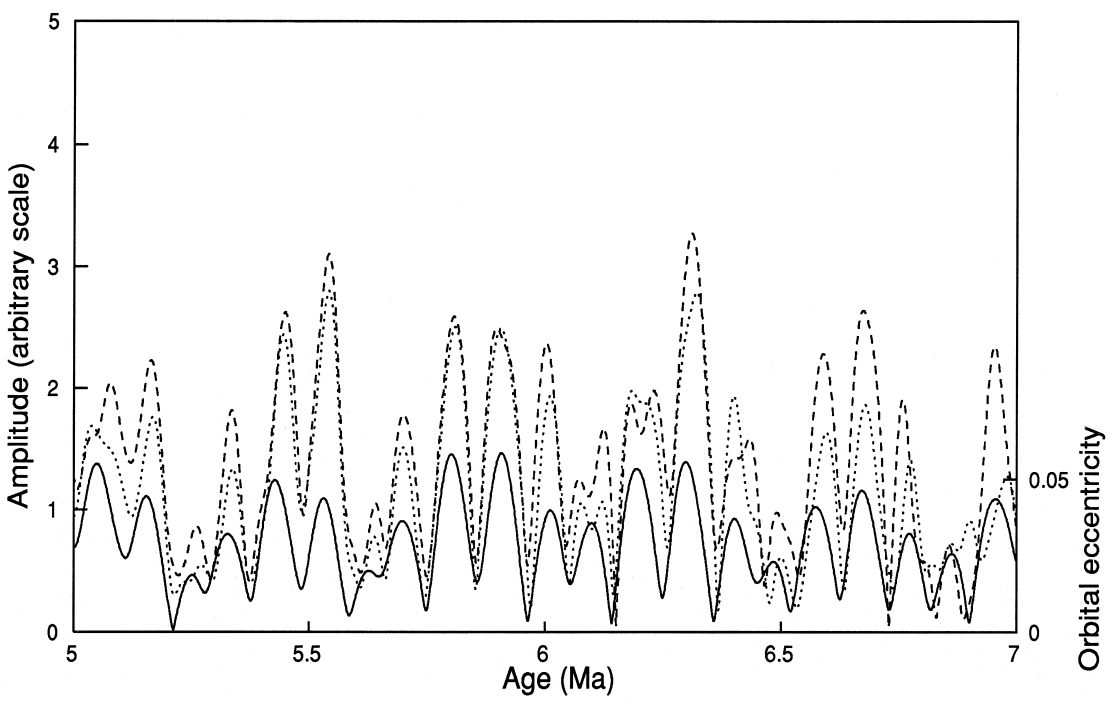

B

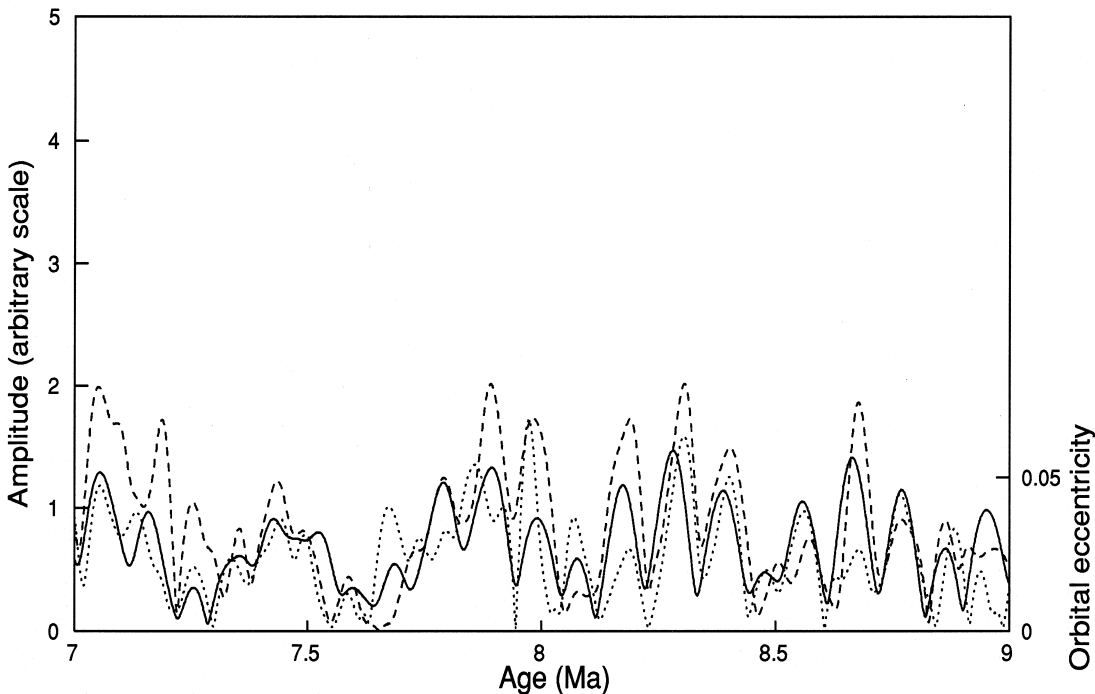

Figure 3. Amplitude of the 21-k.y. signal of the magnetic susceptibility record at Site 925 (dotted line) and 926 (dashed line), as determined by complex demodulation, compared with the history of orbital eccentricity (Laskar et al., 1993; solid line). A. 5 to 7 Ma. B. 7 to 9 Ma. C. 9 to $11 \mathrm{Ma}$. D. 11 to $13 \mathrm{Ma}$. E. 13 to $15 \mathrm{Ma}$ (note that the interval from 14 to $15 \mathrm{Ma}$ is not tuned).

lation in the Northern Hemisphere and maximum percent carbonate in the sediment. Complex demodulation of the benthic $\delta^{18} \mathrm{O}$ record at 0.0244 cycles/k.y. (Fig. 6) shows that over the interval from 4.944 Ma to $7.35 \mathrm{Ma}$ the phase remains rather steady, but that in the older interval it is more variable. Figure 5 also demonstrates that during the $4.944 \mathrm{Ma}$ to $7.35 \mathrm{Ma}$ interval the benthic $\delta^{18} \mathrm{O}$ record contains proportionately more power (and more coherent power) related to the obliquity frequency, whereas the record of terrigenous accumulation (Fig. 5A) is dominated by precession-related variability. We have also performed cross-spectral analysis against insolation for two other variables (summarized in Table 3). Figures 5C and 5D show amplitude, coherent amplitude, and phase of $\delta^{13} \mathrm{C}$ and coarse fraction, respectively. The coarse fraction is made up almost exclusively of foraminifers so that low percent coarse fraction implies dissolution of the foraminiferal shells. The $\delta^{13} \mathrm{C}$ record examined is the one obtained for benthic foraminifers. Shackleton and Hall (this volume) show that, over the time range where $\delta^{13} \mathrm{C}$ data exist both for bulk fine fraction and for benthic foraminifers, the two records are similar and are in phase at the obliquity frequency. In the time interval investigated, $\delta^{13} \mathrm{C}$ shows significant power related to both obliquity and eccentricity. In the obliquity band heavy $\delta^{13} \mathrm{C}$ lags high-latitude insolation, while high percent coarse fraction leads insolation (i.e., maximum dissolution lags maximum high-latitude insolation), so that more dissolved samples are associated with heavier $\delta^{13} \mathrm{C}$. If dissolution cycles were caused by deep-water circulation changes (for example, changes in the relative contributions of Antarctic Bottom Water and North Atlantic Deep Water), (a) we would expect no phase lag with respect to deep temperatures indicated by benthic $\delta^{18} \mathrm{O}$, and (b) we would expect more intense dissolution to be associated with light $\delta^{13} \mathrm{C}$ values. Thus we conclude that $41 \mathrm{k}$.y. dissolution cycles arose from changes in ocean chemistry that lagged the climatic forcing, perhaps due to the long residence time of carbon in the ocean.

The character of the records is somewhat different in the older part of the record investigated; excursions in the percentage of car- 


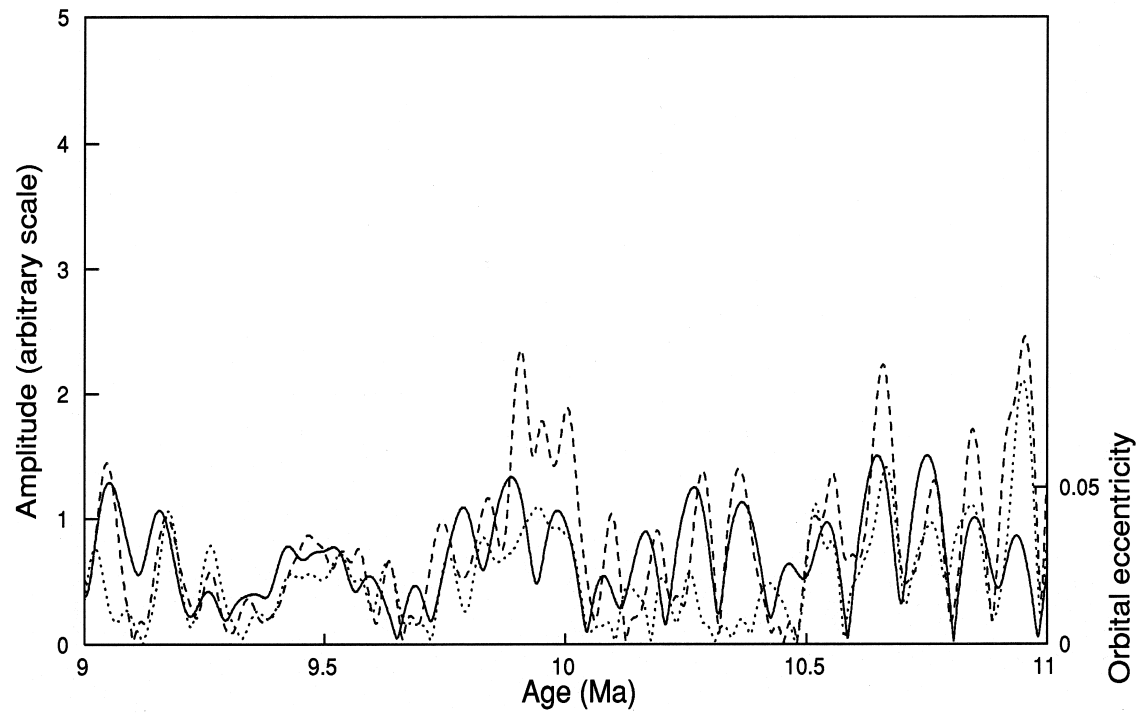

D

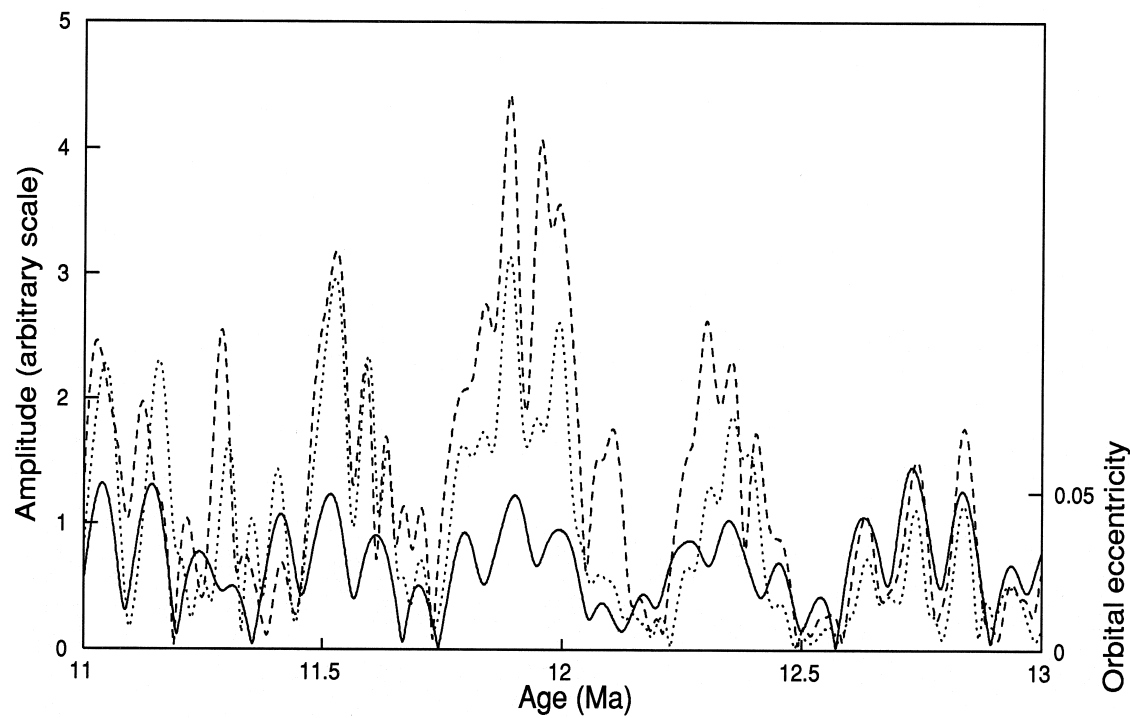

Figure 3 (continued).

bonate are more extreme, and it appears that dissolution has had a major impact on percent carbonate. Because we demonstrate that in the $4.944 \mathrm{Ma}$ to $7.35 \mathrm{Ma}$ interval, dissolution lags orbital forcing, it is likely that in the older part of the record the assumption of a zero phase lag embedded in our tuning is incorrect. Additional $\delta^{18} \mathrm{O}$ data might help to establish a more probable phase relationship in this interval, but the data available so far are discouraging; there is less $\delta^{18} \mathrm{O}$ variance in the obliquity band in the data between $11 \mathrm{Ma}$ and $13 \mathrm{Ma}$ and the phase appears to be less consistent (Fig. 6).

\section{DISCUSSION: COMPARISON WITH THE MAGNETIC POLARITY TIME SCALE OF HILGEN ET AL. (1995)}

Hilgen et al. (1995) have recently calibrated magnetic reversals between C3An.2n (o) and C4Ar.2n (o) (6.677 Ma to 9.679 Ma) to an orbital template using sections in southern Italy (Gibliscemi, Sicily) and Greece (Faneromeni and Kastelli, Crete; Metochia, Gavdos).
Their calibrations result in adjustments of the order of 100 k.y. to the Miocene portion of the Leg 138 time scale. It is not possible to directly compare our results with theirs, because no polarity reversals were detected at Site 926, while no biostratigraphic datums that have extraMediterranean utility have been reported in the sequences examined by Hilgen et al. (1995). The time scale presented in this chapter results in adjustments in the same direction and of the same order to the ages of calcareous nannofossil datums that were based on the Leg 138 time scale. Raffi et al. (this volume) evaluate these differences. Our tuning appears to be consistent with that generated by Hilgen et al. (1995) over the interval that is common to both, as well as being highly consistent with the interval in common with the directly tuned portion of the Leg 138 time scale (about 5.0 to 5.5 Ma).

\section{SEDIMENTATION RATES AND FLUXES}

To proceed with the evaluation of the record, it is necessary to make a conversion of the MST data to percent carbonate. On board 


\section{$E$}

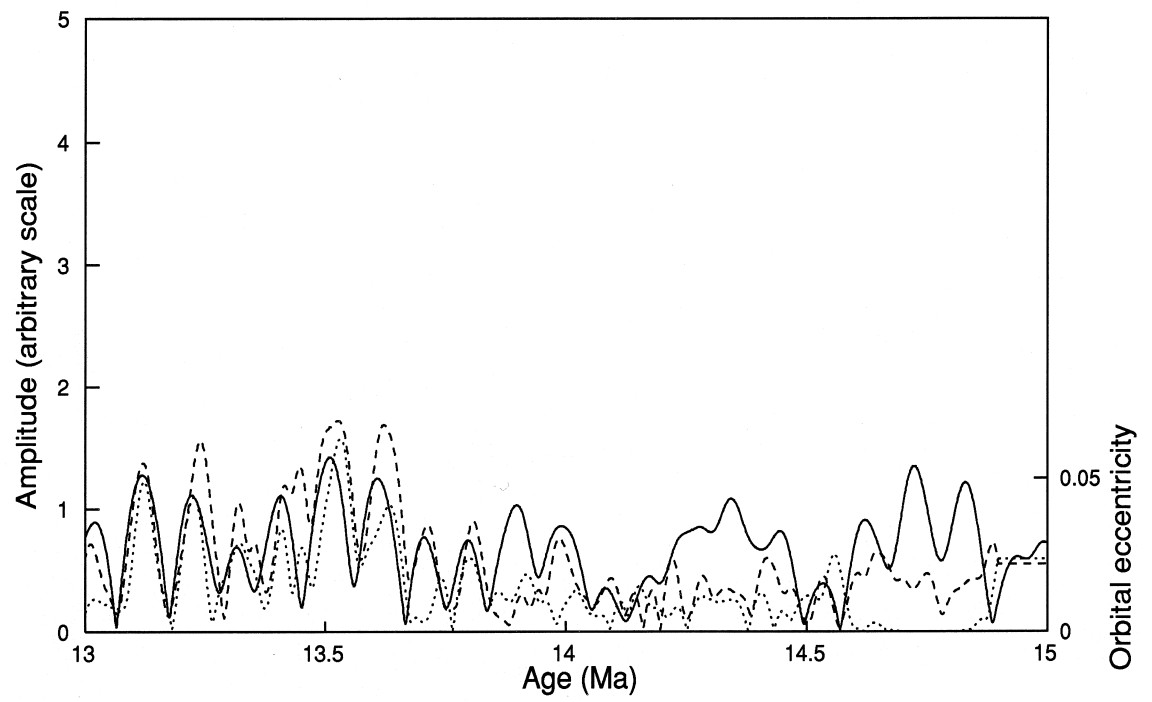

Figure 3 (continued).

ship it was discovered that the natural gamma data, although suffering from a low signal-to-noise ratio, provide the most robust estimate of percent carbonate. Using both shipboard and additional discrete carbonate measurements, we obtained a new regression between natural gamma (expressed as counts per gram dry sediment, estimated by means of the MST gamma-ray attenuation porosity evaluator [GRAPE] density estimates) and percent carbonate. This relationship was then used to obtain a continuous but noisy percent carbonate record from the natural gamma data. This, in turn, was used to determine point-by-point calibration functions relating susceptibility (per gram dry sediment) and reflectance to percent carbonate. These calibration functions were smoothed over about $40 \mathrm{k}$.y. and reapplied to obtain two continuous high-resolution percent carbonate records from the susceptibility and reflectance data. From these a stack of percent carbonate estimates was generated after eliminating those reflectance estimates predicting less than $40 \%$ carbonate (where the reflectance becomes a less sensitive estimator, while susceptibility becomes a more sensitive parameter).

To exploit this high-frequency carbonate reconstruction in terms of fluxes, it is necessary to make an assumption regarding the dominant variability embedded in the percent carbonate record. Close to the carbonate compensation depth (CCD) it is inherently likely that variations in the CCD will provide the chief forcing on percent carbonate, but at shallower water depths such as at Sites 925 and 926 it is unlikely that there would be a clear signal in the percent carbonate record, unless the controlling variable was either the terrigenous input or the surface carbonate productivity. Samples with a very low percentage of coarse fraction show intense dissolution of the remaining foraminifers, so that we assume that varying dissolution was a control on foraminiferal preservation. However, for the interval 4.944 Ma to 7.35 Ma, a scatter plot of coarse fraction as a proportion of total carbonate, vs. the ratio of fine-fraction carbonate to terrigenous matter (Fig. 7), shows that even when dissolution of the foraminifers is relatively intense the loss of fine carbonate is not of great significance. Neither fine-fraction $\delta^{13} \mathrm{C}$ nor fine-fraction $\delta^{18} \mathrm{O}$ display significant precession-related variance (Shackleton and Hall, this volume), arguing against surface oceanography providing the forcing. On the other hand, the flux of terrigenous matter does display power at the eccentricity frequency, which is probably present as a result of some nonlinearity in the response to precession forcing. For these reasons, we have proceeded with a model in which the mass accumulation rate of fine carbonate is assumed to be constant between age control points, and the fluxes of terrigenous matter and of coarse fraction are allowed to vary. Using this model, we generated records of the flux of terrigenous matter, of carbonate, and of coarse fraction (greater than $63 \mu \mathrm{m}$ ) at Site 926 (Fig. 8) over the interval for which this appears to be an appropriate model. The coarse fraction is composed almost entirely of foraminifers and very few fragments of fish teeth.

As is to be expected given the model that we used, cross-spectral analysis (Fig. 9; Table 3) shows terrigenous flux to have strong precession-related variability that is in phase with orbital forcing. A surprising result, which is not an artifact of the model, is that the flux of coarse fraction is not in phase with obliquity. In the interval between about $5 \mathrm{Ma}$ and 7.5 Ma, minimum coarse-fraction flux (i.e., maximum dissolution) lags peak high-latitude isolation by about $90^{\circ}$ and is approximately in phase with most positive $\delta^{13} \mathrm{C}$. As mentioned above, this is strong evidence that changing ocean chemistry, rather than changing deep circulation, provides the causal link. If these changes entailed only carbon, one should still expect to find increased dissolution associated with lighter $\delta^{13} \mathrm{C}$, so that changes in nutrients may also have occurred. In the older part of the record the same relationship does not hold. In much of the older section, high percent coarse fraction is in phase with high percent carbonate, suggesting that in this interval obliquity-related variations in percent carbonate may have been controlled by dissolution rather than by terrigenous dilution. In Figure 10 we show computed fluxes for the whole interval using a naive model whereby constant linear accumulation is assumed between age control points. High-frequency variations that are shown in Figure 10 are misleading, because between age control points the flux of carbonate must be represented as rising whenever the flux of noncarbonate is shown as falling. Nevertheless those flux variations having a long period (several control points) are correctly portrayed for all components.

\section{SUMMARY}

The lithologic records of ODP Sites 926 and 925 have been tuned astronomically using the same astronomical solution (Laskar et al., 1993) that has been used successfully for tuning Pliocene and late Miocene sequences in the Mediterranean region (Hilgen et al., 1995). The reliability of the tuning is indicated by the 400-k.y. and 100-k.y. eccentricity modulation of the 21-k.y. precession signal detected in the lithologic cyclicity. Between 4.944 and 7.35 Ma the assumption on which the calibration is based, that terrigenous input varied in 
A

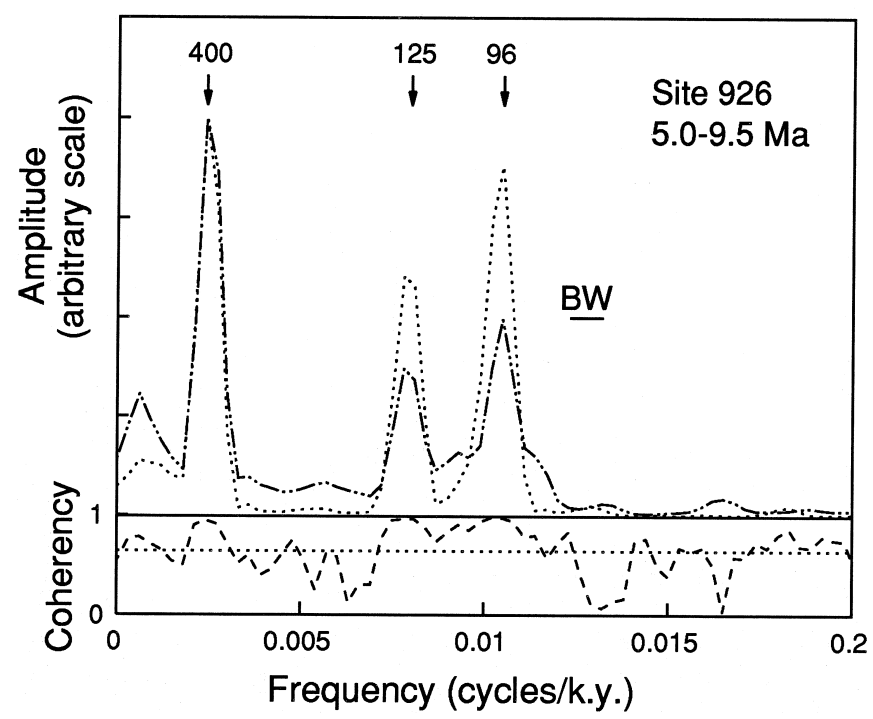

C

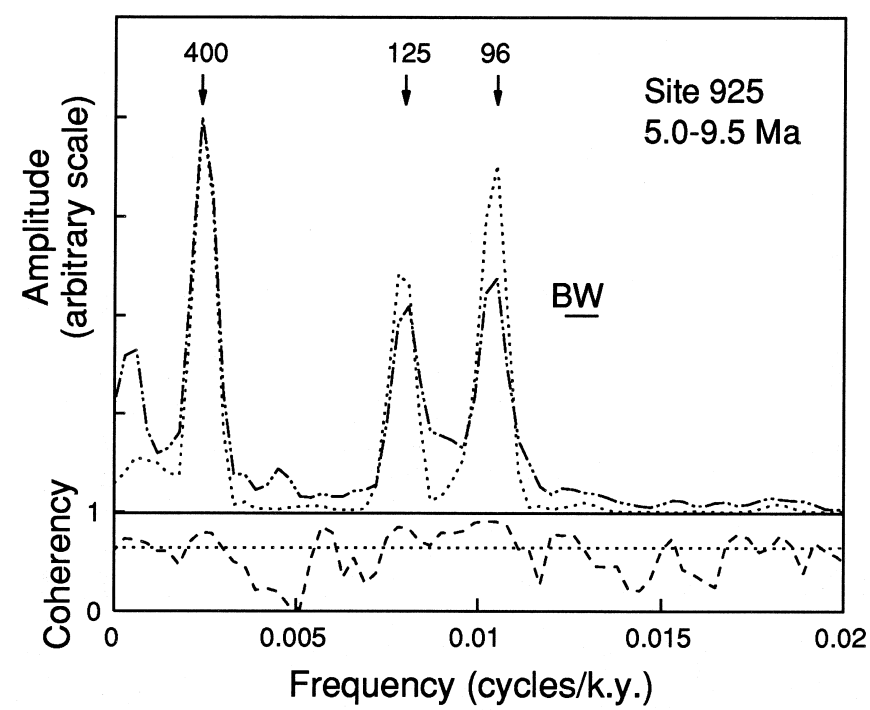

B

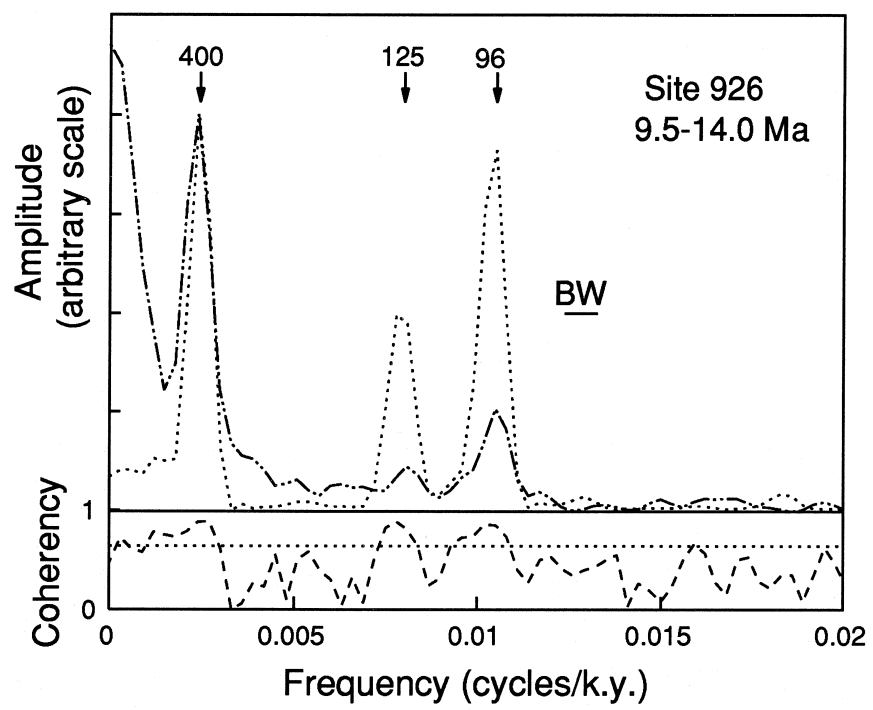

D

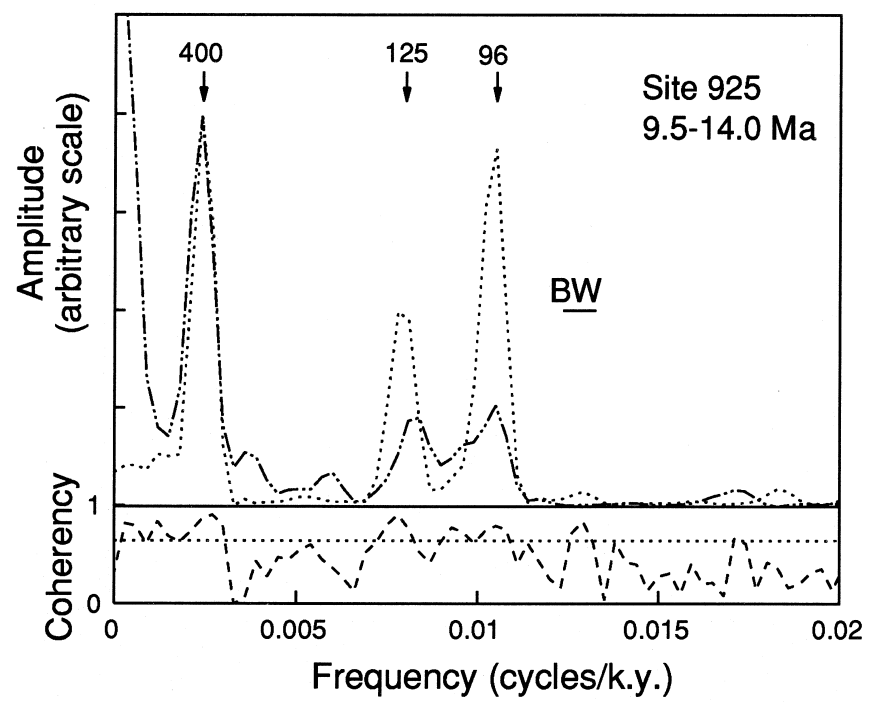

Figure 4. A, B. Cross-spectral analysis of amplitude of the 21-k.y. signal at Site 926 (from Fig. 3) vs. eccentricity. C, D. Cross-spectral analysis of amplitude of the 21-k.y. signal at Site 925 (from Fig. 3) vs. eccentricity. Both are calculated separately over the interval 5 to $9.5 \mathrm{Ma}$ (A, C) and 9.5 to 14 Ma (B, D), sampled at 10-k.y. intervals. The solid line shows coherency (scaled between 0 and 1), the dotted line the spectrum of eccentricity, and the dash-dotted line the spectrum of the signal amplitude (arbitrary scale). Arrows indicate the approximate periods (k.y.) with which eccentricity varies.

phase with Northern Hemisphere insolation, is very robust. In this interval, deep-water temperature (derived from $\delta^{18} \mathrm{O}$ ) varied in phase with high-latitude insolation (at the obliquity frequency), while carbonate dissolution (indicated by reduced percent coarse fraction) and ocean chemistry $\left(\delta^{13} \mathrm{C}\right)$ lagged insolation. Although the tuning was successfully extended to $14 \mathrm{Ma}$, parts of the deeper section (between 7 and $14 \mathrm{Ma}$ ) document a somewhat different response to orbital forcing; cyclic changes in carbonate dissolution may have played a more important role relative to terrigenous input in this interval than in the 4.944 to $7.35 \mathrm{Ma}$ interval.

\section{ACKNOWLEDGMENTS}

We thank the crew of the JOIDES Resolution for enabling the Leg 154 Shipboard Scientific Party to return with such beautiful cores, and our scientific and technical colleagues on board the ship for sharing 8 weeks of exciting, hard work for the benefit of a generation of Atlantic-loving paleoceanographers. The labor-intensive job of tuning all the GRAPE density records would have been impossible without the support of NERC through grant GST/02/554. We thank Terri King for help with mathematical methods and Jan Backman who gen- 
erously shared his unpublished carbonate determinations as well as providing a continuous update on the biostratigraphy of Sites 925 and 926. We thank N.G. Pisias and F.J. Hilgen for their helpful reviews of the submitted manuscript, and Terri King, Peter DeMenocal, and Jan Backman in particular for valuable discussions at several stages in its progress.

\section{REFERENCES}

Berger, A., 1988. Milankovitch theory and climate. Rev. Geophys., 26:624657.

Berger, A., and Loutre, M.F., 1991. Insolation values for the climate of the last 10 million years. Quat. Sci. Rev., 10:297-317.

Cande, S.C., and Kent, D.V., 1992. A new geomagnetic polarity time scale for the Late Cretaceous and Cenozoic. J. Geophys. Res., 97:1391713951.

Chaisson, W.P., and Leckie, R.M., 1993. High-resolution Neogene planktonic foraminifer biostratigraphy of Site 806, Ontong Java Plateau (western equatorial Pacific). In Berger, W.H., Kroenke, L.W., Mayer, L.A., et al., Proc. ODP, Sci. Results, 130: College Station, TX (Ocean Drilling Program), 137-178.

Hilgen, F.J., 1991a. Astronomical calibration of Gauss to Matuyama sapropels in the Mediterranean and implication for the geomagnetic polarity time scale. Earth Planet. Sci. Lett., 104:226-244.

, 1991b. Extension of the astronomically calibrated (polarity) time scale to the Miocene/Pliocene boundary. Earth Planet. Sci. Lett., 107:349-368

Hilgen, F.J., Krijgsman, W., Langereis, C.G., Lourens, L.J., Santarelli, A., and Zachariasse, W.J., 1995. Extending the astronomical (polarity) time scale into the Miocene. Earth Planet. Sci. Lett., 136:495-510.

Imbrie, J., Hays, J.D., Martinson, D.G., McIntyre, A., Mix, A.C., Morley, J.J., Pisias, N.G., Prell, W.L., and Shackleton, N.J., 1984. The orbital theory of Pleistocene climate: support from a revised chronology of the marine $\delta^{18} \mathrm{O}$ record. In Berger, A., Imbrie, J., Hays, J., Kukla, G., and Saltzman, B. (Eds.), Milankovitch and Climate (Pt. 1), NATO ASI Ser. C, Math Phys. Sci., 126: Dordrecht (D. Reidel), 269-305.

Jenkins, G.M., and Watts, D.G., 1968. Spectral Analysis and Its Applications: San Francisco (Holden Day).

Kutzbach, J.E., and Guetter, P.J., 1984. The sensitivity of monsoon climates to orbital parameter changes for 9,000 years BP: experiments with the
NCAR general circulation model. In Berger, A., Imbrie, J., Hays, J., Kukla, G., and Saltzman, B. (Eds.), Milankovitch and Climate (Vol. 2): Hingham, MA (D. Reidel), 801-820.

Laskar, J., Joutel, F., and Boudin, F., 1993. Orbital, precessional, and insolation quantities for the Earth from $-20 \mathrm{Myr}$ to $+10 \mathrm{Myr}$. Astron. Astrophys., 270:522-533.

Lourens, L.J., Hilgen, F.J., Zachariasse, W.J., van Hoof, A.A.M., Antonarakou, A., and Vergnaud-Grazzini, C., in press. Evaluation of the PlioPleistocene astronomical time scale. Paleoceanography.

Quinn, T.R., Tremaine, S., and Duncan, M., 1991. A three million year integration of the Earth's orbit. Astron. J., 101:2287-2305.

Shackleton, N.J., Baldauf, J.G., Flores, J.-A., Iwai, M., Moore, T.C. Jr., Raffi, I., and Vincent, E., 1995a. Biostratigraphic summary for Leg 138. In Pisias, N.G., Mayer, L.A., Janecek, T.R., Palmer-Julson, A., and van Andel, T.H. (Eds.) Proc. ODP, Sci. Results, 138: College Station, TX (Ocean Drilling Program), 517-536.

Shackleton, N.J., Crowhurst, S., Hagelberg, T., Pisias, N.G., and Schneider, D.A., 1995b. A new late Neogene time scale: application to Leg 138 sites. In Pisias, N.G., Mayer, L.A., Janecek, T.R., Palmer-Julson, A., and van Andel, T.H. (Eds.), Proc. ODP, Sci. Results, 138: College Station, TX (Ocean Drilling Program), 73-101.

Shackleton, N.J., Hagelberg, T.K., and Crowhurst, S.J., 1995c. Evaluating the success of astronomical tuning: Pitfalls of using coherence as a criterion for assessing pre-Pleistocene timescales. Paleoceanography, 10:693-697.

Shackleton, N.J., and Imbrie, J., 1990. The $\delta^{18} \mathrm{O}$ spectrum of oceanic deep water over a five-decade band. Clim. Change, 16:217-230.

Shipboard Scientific Party, 1995a. Explanatory notes. In Curry, W.B., Shackleton, N.J., Richter, C., et al., Proc. ODP, Init. Repts., 154: College Station, TX (Ocean Drilling Program), 11-38.

, 1995b. Site 926. In Curry, W.B., Shackleton, N.J., Richter, C., et al., Proc. ODP, Init. Repts., 154: College Station, TX (Ocean Drilling Program), 153-232.

Date of initial receipt: 4 December 1995

Date of acceptance: 19 August 1996

Ms 154SR-102 
A

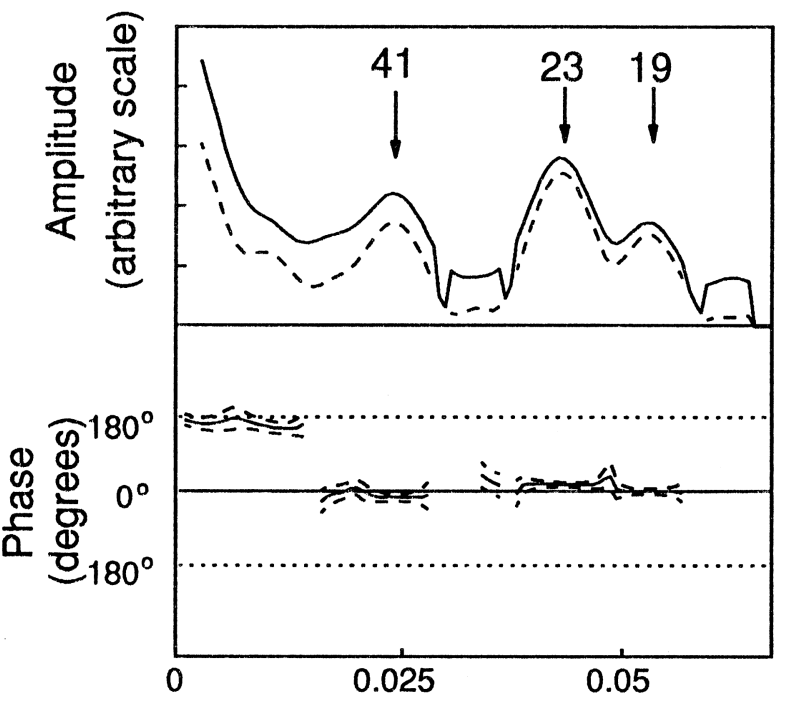

C

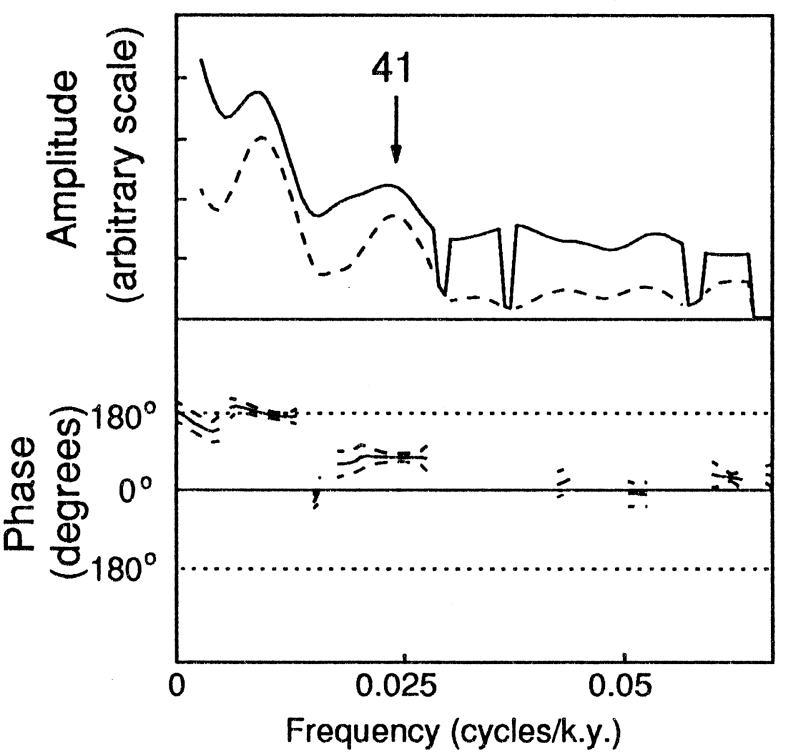

B

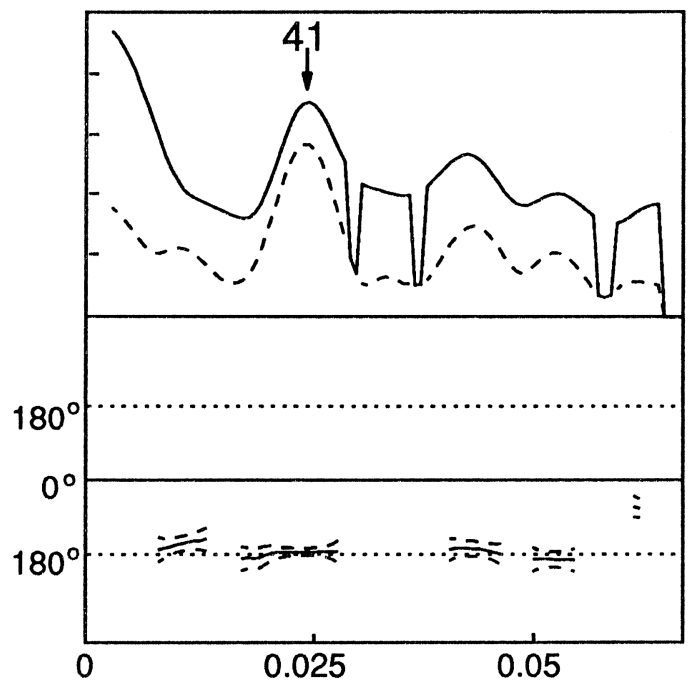

D

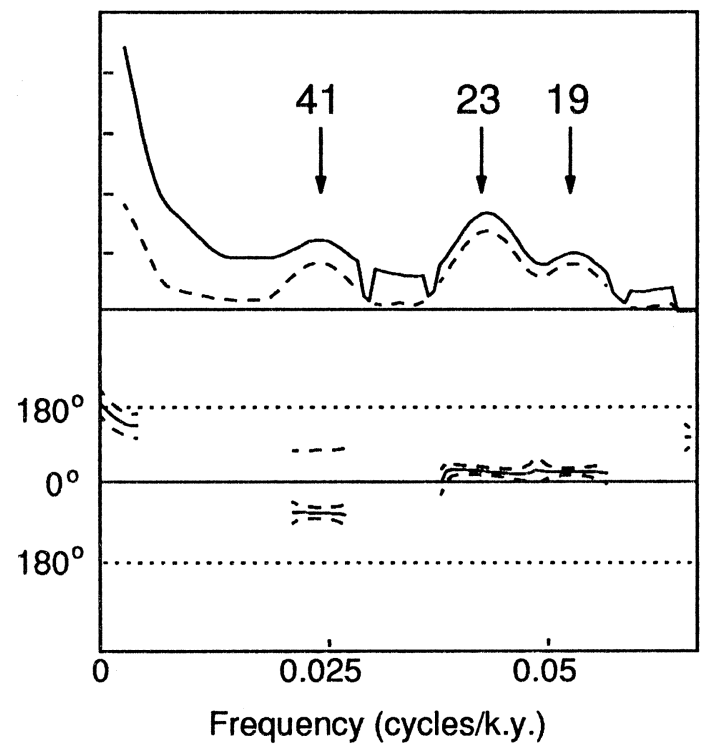

Figure 5. Cross-spectral analyses (amplitude, coherent amplitude, and phase) of (A) logarithm of (carbonate/noncarbonate), $(\mathbf{B}) \delta^{18} \mathrm{O}$ in benthic foraminifers, $(\mathbf{C})$ $\delta^{13} \mathrm{C}$ in benthic foraminifers, and (D) wt $\%$ coarse fraction (over $63 \mu \mathrm{m}$ ), all vs. an orbital signal $\left(65^{\circ}\right.$ summer insolation with eccentricity) for the interval 4.944 to 7.35 Ma using the time scale developed by tuning the lithologic record. Arrows indicate the approximate periods (k.y.) with which insolation varies. In panel B, the $\delta^{18} \mathrm{O}$ phase was computed for negative $\delta^{18} \mathrm{O}$ (i.e., positive temperature). In panel $\mathrm{D}$ percent coarse fraction is shown as leading insolation by about $90^{\circ}$ at the obliquity frequency; this is interpreted (dashed line) as dissolution of coarse fraction lagging insolation in the obliquity band by about $90^{\circ}$. 
Table 3. Coherence and phase estimates (with uncertainty) for cross-spectral analyses discussed.

\begin{tabular}{|c|c|c|c|c|c|c|c|c|}
\hline \multicolumn{9}{|c|}{ Interval from 4.944 to $7.350 \mathrm{Ma}$ (linear interpolation) } \\
\hline \multirow[b]{2}{*}{ Parameter } & \multicolumn{2}{|c|}{100 k.y. } & \multicolumn{2}{|c|}{41 k.y. } & \multicolumn{2}{|c|}{23 k.y. } & \multicolumn{2}{|c|}{19 k.y. } \\
\hline & Coh & Phase & Coh & Phase & Coh & Phase & Coh & Phase \\
\hline $\log (\mathrm{ca} /$ nonca $)$ & 0.81 & $153 \pm 10$ & 0.92 & $-14 \pm 6$ & 0.96 & $16 \pm 4$ & 0.96 & $-1 \pm 4$ \\
\hline ben $\delta^{18} \mathrm{O}$ & 0.47 & & 0.82 & $-173 \pm 10$ & 0.48 & $-170 \pm 24$ & 0.61 & $162 \pm 18$ \\
\hline ben $\delta^{13} \mathrm{C}$ & 0.84 & $171 \pm 9$ & 0.80 & $72 \pm 11$ & 0.29 & & 0.17 & \\
\hline$\% \mathrm{cf}$ & 0.27 & & 0.79 & $-73 \pm 11$ & 0.81 & $24 \pm 10$ & 0.82 & $21 \pm 10$ \\
\hline \multicolumn{9}{|c|}{ Interval from 10.974 to $13.212 \mathrm{Ma}$ (linear interpolation) } \\
\hline & \multicolumn{2}{|c|}{100 k.y. } & \multicolumn{2}{|c|}{41 k.y. } & \multicolumn{2}{|c|}{23 k.y. } & \multicolumn{2}{|c|}{19 k.y. } \\
\hline Parameter & Coh & Phase & Coh & Phase & Coh & Phase & Coh & Phase \\
\hline ben $\delta^{18} \mathrm{O}$ & 0.57 & $-159 \pm 21$ & 0.85 & $141 \pm 9$ & 0.74 & $167 \pm 13$ & 0.14 & \\
\hline ben $\delta^{13} \mathrm{C}$ & 0.45 & & 0.66 & $-8 \pm 17$ & 0.52 & & 0.48 & \\
\hline \multicolumn{9}{|c|}{ Interval 4.944 to $7.350 \mathrm{Ma}$ (interpolation on accumulated mass of fine fraction carbonate) } \\
\hline & \multicolumn{2}{|c|}{100 k.y. } & \multicolumn{2}{|c|}{41 k.y. } & \multicolumn{2}{|c|}{23 k.y. } & \multicolumn{2}{|c|}{19 k.y. } \\
\hline Parameter & Coh & Phase & Coh & Phase & Coh & Phase & Coh & Phase \\
\hline terr flux & 0.79 & $-15 \pm 11$ & 0.86 & $-169 \pm 8$ & 0.95 & $-166 \pm 5$ & 0.94 & $179 \pm 5$ \\
\hline cf flux & 0.16 & & 0.74 & $-88 \pm 13$ & 0.61 & $30 \pm 18$ & 0.64 & $25 \pm 17$ \\
\hline \multicolumn{9}{|c|}{ Interval 5.001 to 13.260 (linear interpolation) } \\
\hline & \multicolumn{2}{|c|}{100 k.y. } & \multicolumn{2}{|c|}{41 k.y. } & \multicolumn{2}{|c|}{23 k.y. } & \multicolumn{2}{|c|}{19 k.y. } \\
\hline Parameter & Coh & Phase & Coh & Phase & Coh & Phase & Coh & Phase \\
\hline fine $\delta^{13} \mathrm{C}$ & 0.93 & $172 \pm 9$ & 0.90 & $179 \pm 11$ & 0.76 & $-175 \pm 19$ & 0.85 & $68 \pm 14$ \\
\hline
\end{tabular}

Note: All spectra were calculated against orbital data (obliquity and climatic precession combined as for summer insolation at $65^{\circ} \mathrm{N}$ together with eccentricity) from Laskar et al. (1993). Discrete sample data (isotope and coarse fraction) were interpolated at 6-k.y. intervals and other (MST-based and reflectance) data at 3-k.y. intervals using the tuned age model discussed in the text. $\mathrm{Coh}=$ coherence, $\log (\mathrm{ca} /$ nonca $)=\log ($ carbonate/noncarbonate $)$, ben $=$ benthic, terr $=$ terrigenous, $\mathrm{cf}=\mathrm{coarse}$ fraction . 


\section{A}

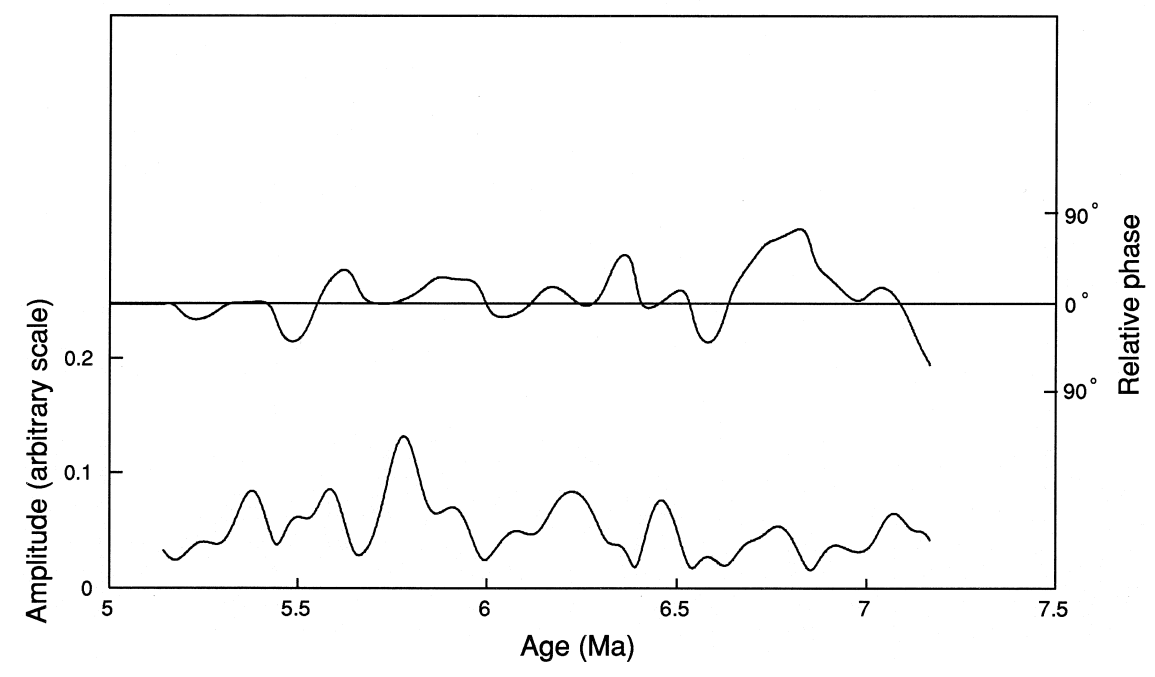

B

Figure 6. Amplitude and phase relative to obliquity of the 41-k.y. signal in $\delta^{18} \mathrm{O}$ at Site 926 (determined by complex demodulation). A. 5 to $7 \mathrm{Ma}$. B. 11 to $13 \mathrm{Ma}$. Over most of the intervals where the amplitude or the 41-k.y. component of $\delta^{18} \mathrm{O}$ is relatively high, the relative phase is close to zero.

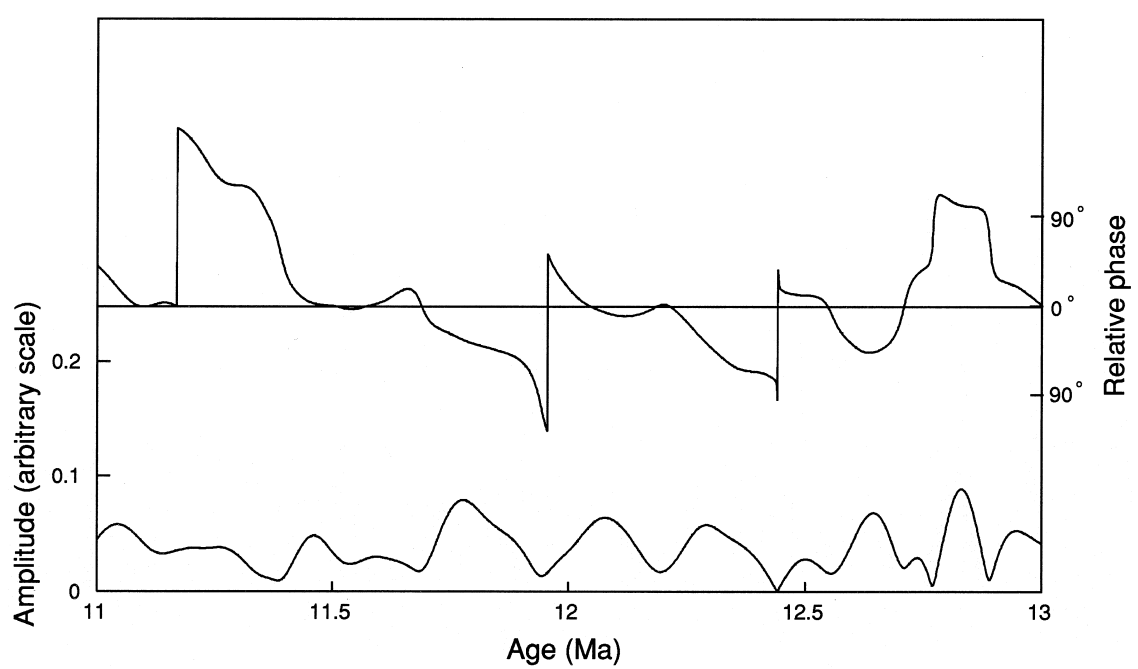




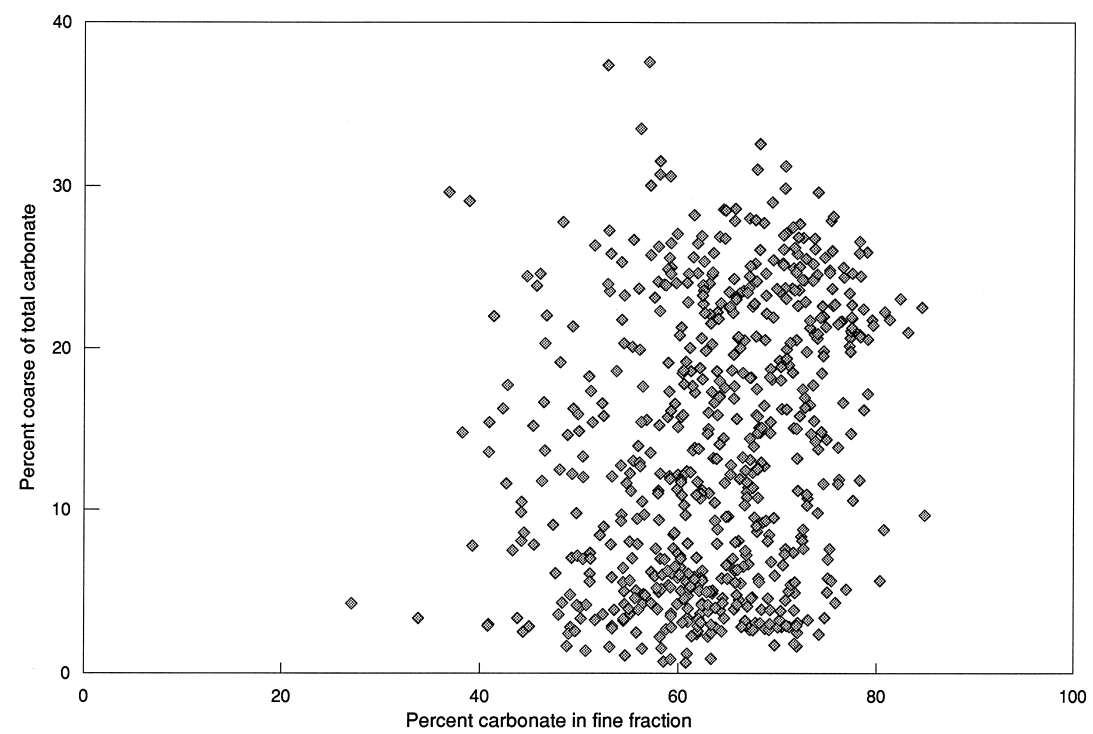

Figure 7. Scatter plot of estimates of the ratio of coarsefraction carbonate to fine carbonate vs. ratio of fine carbonate to noncarbonate, over the 5 to $7 \mathrm{Ma}$ interval at Site 926.
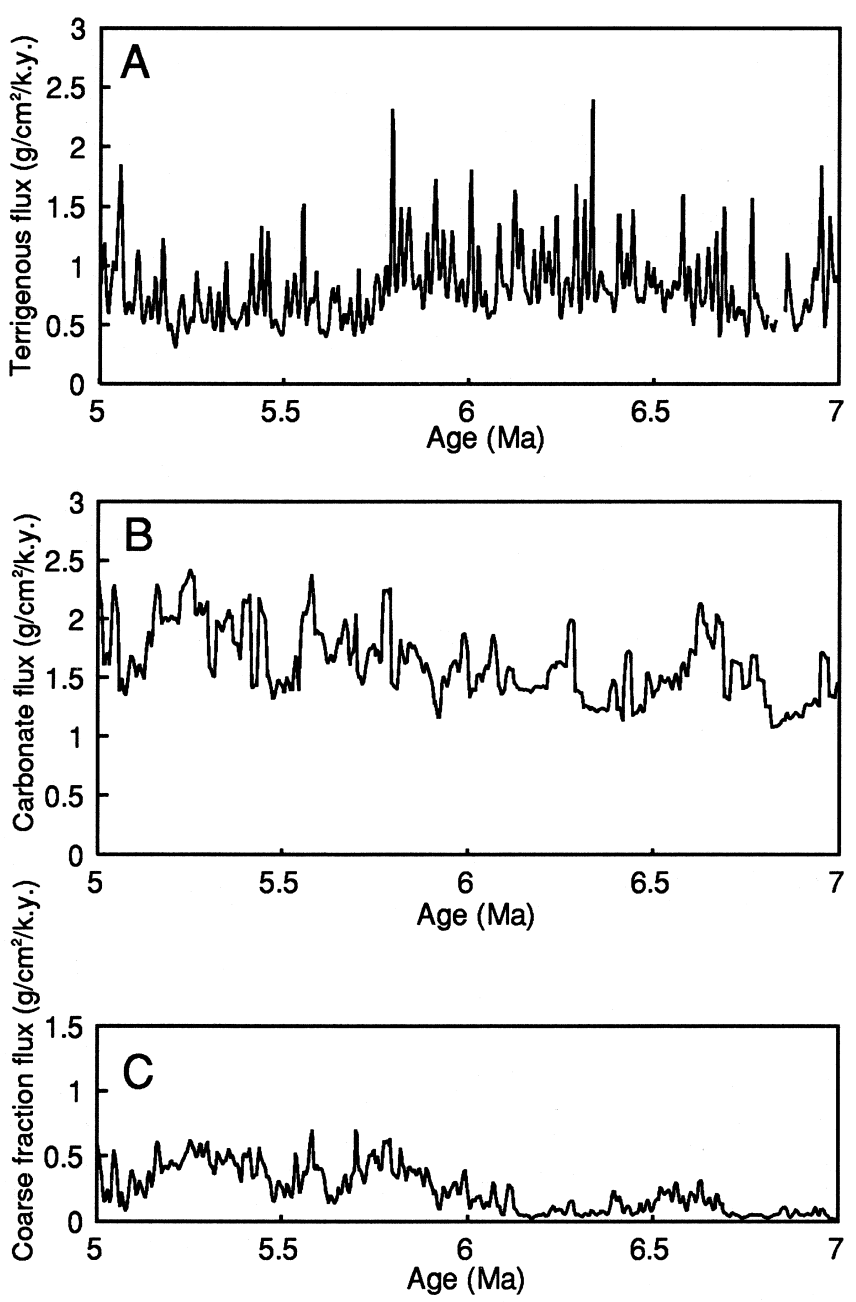

Figure 8. Calculated fluxes of (A) terrigenous component, (B) carbonate, and (C) coarse fraction, at Site 926 between 5 and 7 Ma, computed on the assumption that the accumulation rate of fine-fraction carbonate was constant between age control points. 
A

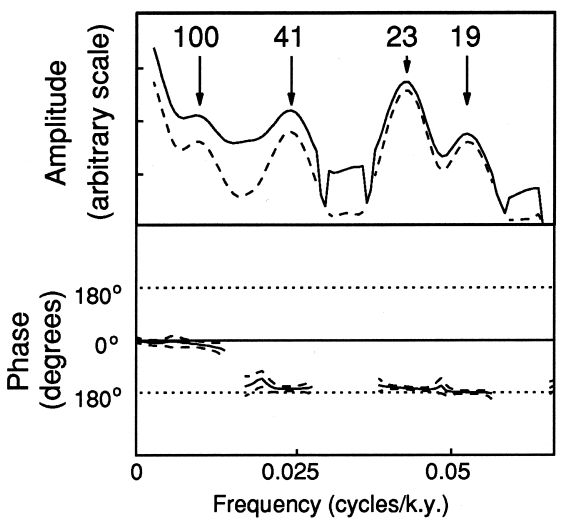

A

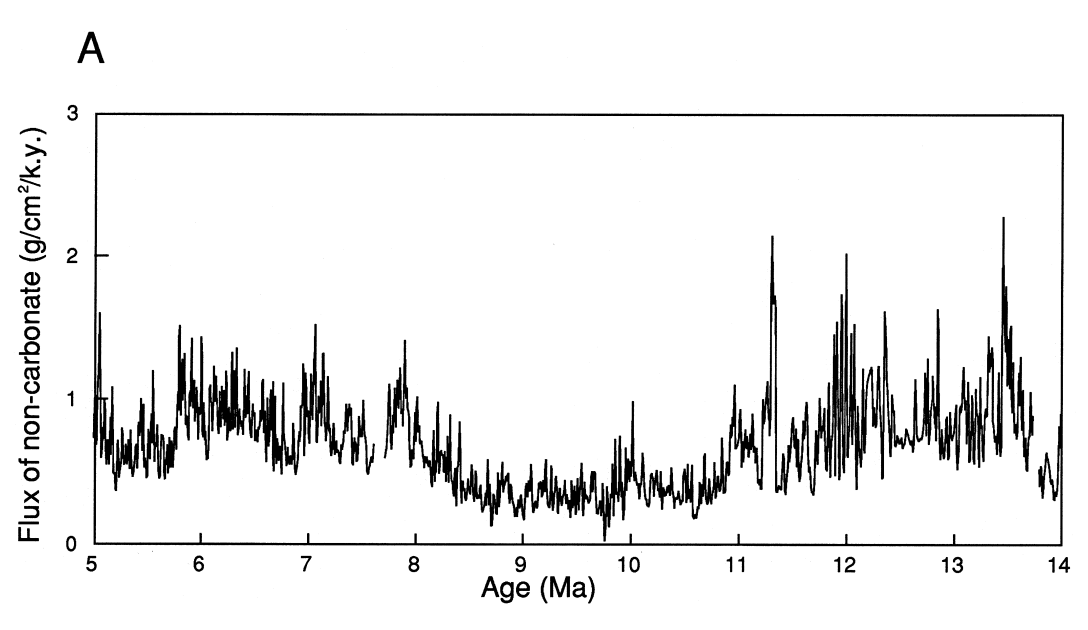

B
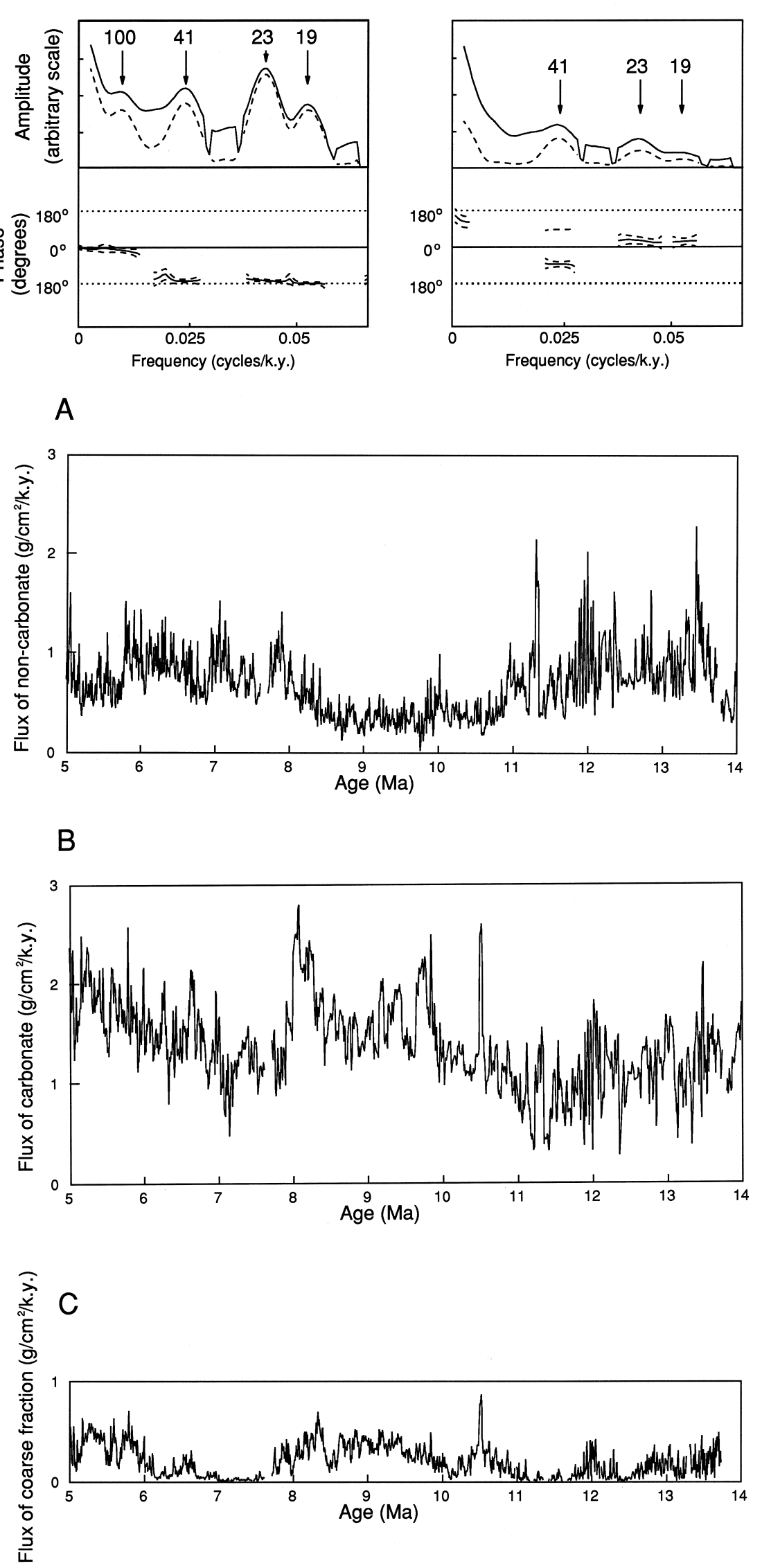

B
Figure 10. Calculated fluxes of (A) terrigenous component (noncarbonate), (B) carbonate, and (C) coarse fraction, all
Figure 9. Cross-spectral analyses (amplitude, coheren (A) the flux of terrigenous (no both vs. $65^{\circ} \mathrm{N}$ summer insolation, 4.944 to $7.35 \mathrm{Ma}$, usin the model whereby the accumulation of fine-fraction carbonate is assumed constant between age control points. Arrows indicate the approximate periods (k.y.) with whic coarse fraction is shown as leading insolation by about $90^{\circ}$, as in Figure 5, this is interpreted (dashed line) as dissolution of coarse fraction lagging insolation in the obliquity band by about $90^{\circ}$.

\footnotetext{
at Site 926 between 5 and 14 Ma.
} 